и качественные дороги» на региональных и межмуниципальных автомобильных дорогах Иркутской области. Режим доступа: http://dor38.ru/bkad-2-0/ (дата обращения 19.10.2021)

9. Богомолов В.Н. Отчет о результатах контрольного мероприятия «Проверка ис- пользования бюджетных ассигнований, направленных на содержание автомобильных дорог общего пользования федерального, регионального и межмуниципального значения в 2018 году и истекшем периоде 2019 года». Режим доступа: c8e8afe3c8e348dc67f36bd6e 24bf5c8.pdf/ (дата обращения 20.10.2021).

Гордеев Клим Игоревич, генеральный директор АНО «Экспертный ичентр СУДЭКС», e-mail: centr-sudex@mail.ru.ru

К ВОПРОСУ О СУДЕБНОЙ СТРОИТЕЛЬНО-ТЕХНИЧЕСКОЙ ЭКСПЕРТИЗЕ

Gorbach P.S., Gordeev K.I.

\title{
TO THE QUESTION OF JUDICIAL CONSTRUCTION-TECHNICAL EXPERTISE
}

\begin{abstract}
Аннотация. $B$ статье рассматриваются проблемь судебной строительнотехнической экспертизы при оценке результатов расчета восстановительной стоимости ремонта помещзений, подвергшихся заливу.
\end{abstract}

Ключевые слова: экспертиза, восстановительный ремонт, стоимость.

Abstract. The article discusses the problems of judicial construction-technical expertise in assessing the results of calculating the replacement cost of repairs to premises exposed to the flooding.

Keywords: expertise, restoration repair, cost.

Строительно-техническая экспертиза (СТЭ) - это установление в процессе контроля градостроительной деятельности соответствия объектов СТЭ обязательным требованиям нормативных правовых актов Российской Федерации, технических регламентов, которые принимаются в установленном порядке и соблюдение которых обеспечивает надлежащее качество и безопасность градостроительной деятельности.

Сложность таких экспертиз порой заключается в том, что сложно сразу сказать, кто виновник обнаруженных отступлений и возможно ли их исправить с минимальными ресурсными затратами. К таким сложным задачам можно отнести залив помещений.

Залив помещения (квартиры) - это ситуация, при которой помещения получают повреждения в результате попадания воды из выше расположенного помещения (помещений); нарушения целостности крыши или наружных стен дома; повреждения оконных блоков, балконов или лоджий; разгерметизации соединений шаровых кранов, гибких подводок или радиаторов отопления (инженерные сети); человеческого фактора (забыли перекрыть воду).

Ремонтно-восстановительные работы, определенные экспертом, должны быть направлены исключительно на ликвидацию последствий залива. Поэтому одной из задач исследования является отделение дефектов, связанных с заливом, от иных (схожих) дефектов (при наличии таковых).

Характер выявленных дефектов определяет выбор видов подлежащих выполнению ремонтно-строительных работ. 
В зависимости от вида и уровня примененных на исследуемом объекте технологий ремонтных работ, наличия (отсутствия) нестандартных дизайнерских решений, качества использованных при первоначальной (имевшей место до залива) отделке квартиры материалов эксперт выбирает метод определения стоимости восстановительного ремонта.

В соответствии с п. 3.27 МДС 8135.2004 при составлении смет (расчетов) могут применяться следующие методы определения стоимости: базисно-индексный, ресурсный, ресурсно-индексный.

Базисно-индексный метод предназначен для приближения стоимости строительства к оптимальному значению, поскольку стоимость ресурсов на текущем уровне цен устанавливается по итогам ежемесячного мониторинга и расчёта средневзвешенных и средних цен, осуществляемого специализированными центрами по ценообразованию в строительстве. Использование индексов на отдельные расходные статьи, ресурсы, а также по конкретным конструктивных решениям, элементам, видам ремонта по отношению к их базисной стоимости позволяет с определенным уровнем точности устанавливать стоимость на актуальном ценовом уровне, при этом исключаются индивидуальные финансовые затраты со стороны подрядной организации. Применение базисно-индексного метода обеспечивает заказчика определенной гарантией на то, что расходы на реализацию объекта строительства или строительную продукцию не будут в итоге превышать средние по региону цены. Рассматриваемый метод предполагает, что участники строительного процесса и рынка в целом, будут ориентироваться на обоснованный затратный уровень, сопутствующие расходы, а не полное возмещение издержек со стороны подрядных организаций по факту.

Ресурсный метод определения стоимости строительства представляет собой калькулирование в текущих (прогнозируемых) ценах и тарифах элементов затрат (ресурсов), необходимых для реализации проекта. Калькулирование ведется на основе выраженной в натуральных измерителях потребности в материалах, изделиях, конструкциях, данных о расстояниях и способах их доставки на место строительства, расхода энергоносителей на технологические цены, времени эксплуатации строительных машин и их состава, затрат труда рабочих.

Ресурсно-индексный метод

калькулирование стоимости работ, сочетая базисно-индексный и ресурсный методы.

При определении стоимости восстановительного ремонта, причиненного затоплением объекта исследования, в основном применяют базисно-индексный подход, что обуславливается спецификой проведенного исследования. Также при оценке учитываются: уровень отделки и качество использованных материалов.

Стоимость строительно-ремонтных работ определяется с учетом того, какие именно работы необходимо произвести. Затраты на ремонт должны быть достаточными, чтобы восстановить помещению первоначальный вид, как до затопления.

Для сравнения рассмотрим объект, для которого рассчитаем стоимость восстановительных работ двумя методами.

Из описания внутренней отделки объекта исследования по данным проведенного осмотра выявлены дефекты и составлена ведомость объемов работ, необходимых для устранения повреждений при затоплении (см. таблицу).

В процессе осмотра выявлены следующие дефекты:

- разбухание дверной коробки (фото 1);

- поперечная трещина плитки (фото 2);

- износ инженерных сетей (фото 3 ).

На основании ведомости объемов работ произведен локальный ресурсный сметный расчет в текущих ценах на 2 квартал 2021 года.

Локальный ресурсный сметный расчет (фото 4) составлен при использовании программного комплекса «Гранд Смета». Применена нормативная база ГЭСН (государственные элементные сметные нормы) - 2001 (редакция 2020 год с изменениями 1, 2, приказ № 871/пр, № 875/пр, №874/пр от 26.12.2019 года. Минстроя РФ от 26.12.2019 года). Государственные элементные сметные нормы (ГЭСН) предназначены для определения состава и потребности в материальнотехнических и трудовых ресурсах, необходимых для выполнения строительных, монтажных, ремонтно-строительных и пусконаладочных работ. 


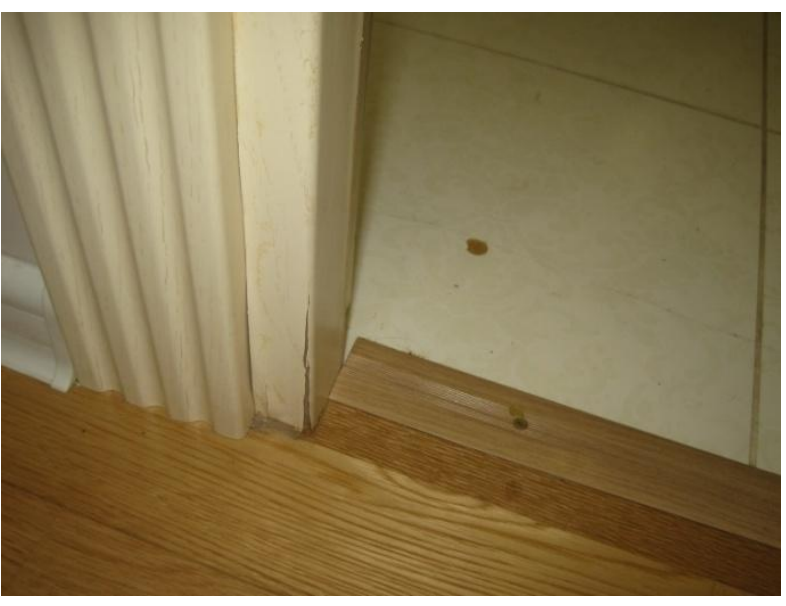

Фото 1 - Разбухание дверной коробки

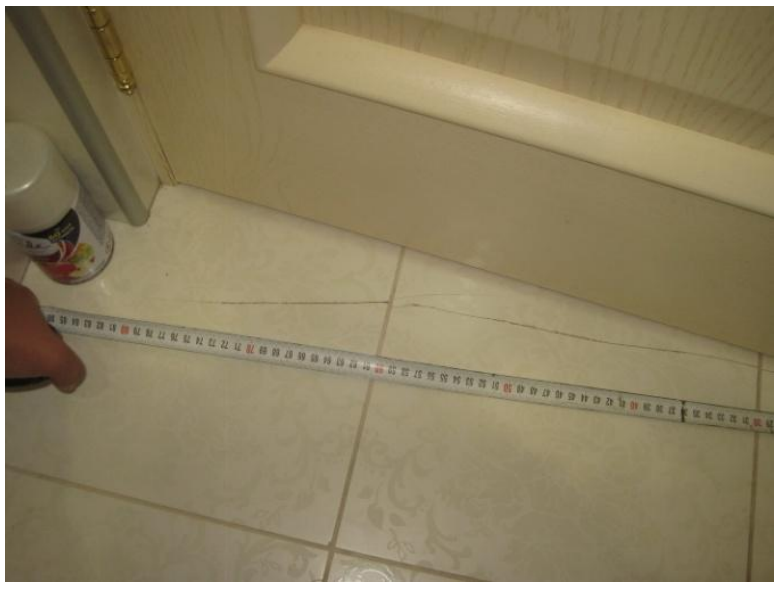

Фото 2 - Поперечная трещина плитки

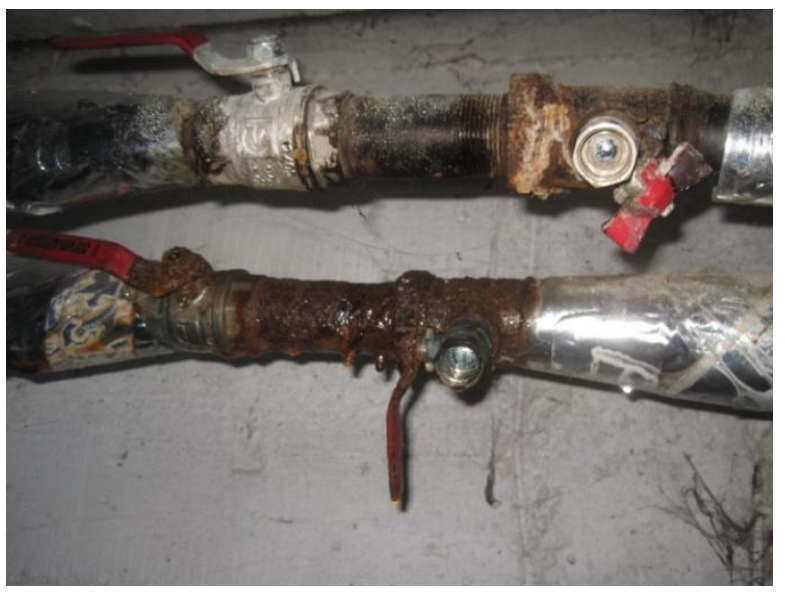

Фото 3 - Износ инженерных сетей

По результатам локального ресурсного сметного расчета сметная стоимость восстановительных работ по устранению повреждений, полученных в результате залива, составила 175,3 тыс. руб.
Таблица - Ведомость объемов работ

\begin{tabular}{|c|c|c|c|}
\hline $\begin{array}{l}\text { № } \\
\Pi / \Pi\end{array}$ & Наименование работ & $\begin{array}{l}\text { Ед. } \\
\text { изм. }\end{array}$ & $\begin{array}{c}\text { Кол- } \\
\text { во }\end{array}$ \\
\hline \multicolumn{4}{|c|}{ Помещение № 1} \\
\hline 1. & $\begin{array}{c}\text { Демонтаж керамической } \\
\text { плитки пола }\end{array}$ & $\mathrm{M}^{2}$ & 3 \\
\hline 2. & Грунтование пола & $\mathrm{M}^{2}$ & 3 \\
\hline 3. & $\begin{array}{c}\text { Облицовка пола } \\
\text { керамической плиткой }\end{array}$ & $\mathrm{M}^{2}$ & 3 \\
\hline 4. & Затирка швов & $\mathrm{M}^{2}$ & 3 \\
\hline 5. & Демонтаж двери & шाT & 1 \\
\hline 6. & Монтаж двери & шाT & 1 \\
\hline \multicolumn{4}{|c|}{ Помещение № 2} \\
\hline 1. & $\begin{array}{c}\text { Демонтаж керамической } \\
\text { плитки пола }\end{array}$ & $\mathrm{M}^{2}$ & 3,4 \\
\hline 2. & Грунтование пола & $\mathrm{M}^{2}$ & 3,4 \\
\hline 3. & $\begin{array}{c}\text { Облицовка пола } \\
\text { керамической плиткой }\end{array}$ & $\mathrm{M}^{2}$ & 3,4 \\
\hline 4. & Затирка швов & $\mathrm{M}^{2}$ & 3,4 \\
\hline 5. & Демонтаж двери & шाT & 1 \\
\hline 6. & Монтаж двери & шाT & 1 \\
\hline \multicolumn{4}{|c|}{ Помещение № 3} \\
\hline 1. & Демонтаж плинтуса & п.м. & 21,6 \\
\hline 2. & $\begin{array}{c}\text { Демонтаж паркетной } \\
\text { доски }\end{array}$ & $\mathrm{M}^{2}$ & 18,9 \\
\hline 3. & Монтаж плинтуса & П.м. & 21,6 \\
\hline 4. & Монтаж паркетной доски & $\mathrm{M}^{2}$ & 18,9 \\
\hline \multicolumn{4}{|c|}{ Прочее } \\
\hline 1. & $\begin{array}{c}\text { Установка } \\
\text { металлического порожка } \\
\text { под дверью }\end{array}$ & шт. & 1 \\
\hline 2. & $\begin{array}{l}\text { Очистка помешений от } \\
\text { строительного мусора }\end{array}$ & T. & 0,1 \\
\hline
\end{tabular}

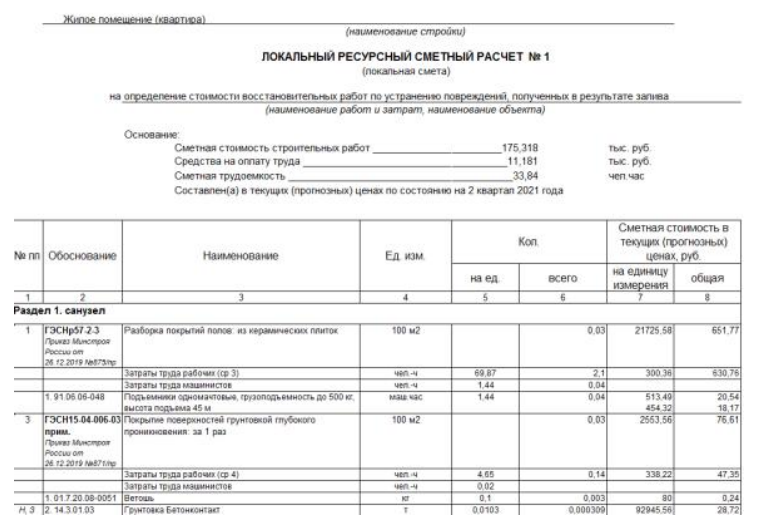

Фото 4 - Локальный ресурсный сметный расчет

По результатам локального ресурсного сметного расчета сметная стоимость восстановительных работ по устранению повреждений, полученных в результате залива, составила 175,3 тыс. руб. 
При использовании ресурсноиндексного метода для последующих расчетов стоимость ремонтных работ на исследуемом объекте определялась на основе нормативной базы стоимости работ (фирменных сметных нормативов) строительных фирм, работающих на рынке ремонта квартир. Расход материалов определялся согласно данным, представленным в сборниках элементных сметных норм (МТСН 81-98 «Общие положения по применению элементно-сметных норм на строительные и ремонтно-строительные работы»). Стоимость материалов определялась исходя из средних рыночных цен в городе на основании анализа предложений соответствующих фирм-поставщиков и торговых предприятий. В результате проведенных расчетов стоимость восстановительных работ по устранению повреждений, полученных в результате залива, составила 420 тыс.руб.

Анализируя полученные данные, видна существенная разница между расчетом, проведенным базисно-индексным и ресурсноиндексным методами. С одной стороны учитываются нормы федеральных расценок, a с другой рыночная стоимость. В этой связи возникает вопрос о методики расчета восстановительного ремонта и необходимости создания единого научно-обоснованного подхода для решения этой задачи.

\section{СПИСОК ЛИТЕРАТУРЫ}

1. СП 13-102-2003 «Правила обследования несущих строительных конструкций зданий и сооружений». Принят комитетом РФ по вопросам архитектуры и строительства 21 августа 2003. Статус - Действующий.

2. ГОСТ 34059-2017 «Инженерные сети зданий и сооружений внутренние. Устройство систем отопления, горячего и холодного водоснабжения. Общие технические требования» (утв. Приказом Федераль- ного агентства по техническому регулированию и метрологии от 16.01.2018г. N 6стПриказ Минэкономразвития России от 18.12.2015 N 953 (ред. от 25.09.2019) «Об утверждении формы технического плана и требований к его подготовке, состава содержащихся в нем сведений, а также формы декларации об объекте недвижимости, требований к ее подготовке, состава содержащихся в ней сведений») (Зарегистрировано в Минюсте России 02.03.2016 N 41304). 